\title{
Electricity Bill Reduction for Crane Industries
}

\author{
Paulraj. $T^{1}$, Infant Santhosh Sherin.F. ${ }^{2}$, Leema Prasilla. $A^{3}$ \\ ${ }^{1,2}$ (Asst. Lecturer, EEE Department, St. Joseph College of Engineering and Technology/SJUIT, Tanzania) \\ ${ }^{3}$ (Lecturer, EEE Department, Don BoscoPolytechnic College, Chennai, India)
}

\begin{abstract}
Most of the industrial electrical loads are inductive in nature. The operation of the inductive leads to reduced power factor in the power system. Decrease in power factor increases the electricity bill. In this paper crane industry with different duty types are analyzed for power factor improvement. Also an innovative reactive power control method is proposed to improve power factor. Simulations are carried out with Matlab-simulink and output results are shown.
\end{abstract}

Keywords: Crane, duty types, power factor, electricity bill, power system.

\section{Introduction}

Three phase induction motors are used in crane industry with S3, S4 and S5 duty types. When the machine runs at different types of load, the performance of the machine will not be identical. Therefore power factor magnitude changes with respect to duty types. Low power factor in the power system increases power system loss, increase in VA rating of the generator thereby increases the electricity bill. In this paper, an innovative method is proposed to improve the power factor.

Three phase induction machine powered by single phase supply generates harmonics. Decrease in power factor is improved by selective harmonic elimination method using buck-boost converter [1]. PWM inverters are used to supply real power and to inject capacitive reactive power for induction machine [2]. Magnetic saturation effect and presence of AC/DC/AC converter are neglected by tracking the rotor flux and speed to improve power factor [3]. Fuzzy logic control algorithm is used for reactive power compensation in doubly fed induction machine.The power factor is independently controlled in synchronously rotating reference frame by decoupled rotor current [4]. Power factor correction based on energy efficiency improvement and optimization method for multiphase machine [5]. To detect the reactive and harmonic current components and to determine the compensating current components to feed back to the system and it has been demonstrated with effective operation and good recital under balanced voltage source conditions instantaneous power theory is used.[3,4] for the purpose of line current compensation. It is also known as active filter in power electronics technology. However, when the voltage source is ominously unbalanced, great errors may be resulted from calculation formula by direct application of the instantaneous power theory [6].This paper focuses on useful method for reactive power compensation in crane industries, so as to reduce the electricity bill.

\section{Power Factor vs Electricity Bill}

Here a case study is taken from TNERC (Tamil Nadu Electricity RegulatoryCommission) - 2013. From table.1 it is observed that electricity bill penalty level increases with reduction of power factor value. Hence it is necessary to improve power factor to reduce penalty level.

\begin{tabular}{|l|l|l|}
\hline S.NO & POWER FACTOR RANGE & ELECTRICITY BILL PENALTY \\
\hline 1 & $0.85 \leq \mathrm{p} . \mathrm{f}<0.90$ & $\begin{array}{l}\text { for every reductionof } 0.01 \text { from } 0.90,1 \% \text { of the } \\
\text { current consumption charges }\end{array}$ \\
\hline 2 & $0.75 \leq \mathrm{P} . \mathrm{f}<0.85$ & $\begin{array}{l}\text { for everyreduction of } 0.01 \text { from } 0.901 \text { of the current } \\
\text { consumption charges }\end{array}$ \\
\hline 3 & P.f $<0.75$ & $\begin{array}{l}\text { for every reductionof } 0.01 \text { from } 0.90 \text { Two per cent of } \\
\text { the current consumption charges }\end{array}$ \\
\hline
\end{tabular}

Table. 1 Power factor VsElectricity bill

\section{System Description}

A balanced $3 \Phi$ voltage source is connected to an inductive load of $3 \Phi$ squirrel cage induction motor and capacitor voltage source inverter (VSI) is connected parallel to the power system is shown in the fig. 1. During starting, running and electric braking operation of a motor consumes different reactive power. Power factor will be affected due to this different duty types. To avoid penalty, it is necessary to improve power factor value.3 $\Phi$ voltage source supplies real current component to the load and VSI. Reactive current component required by the load will be compensated by VSI. The feedback parameters which are used to generate PWM switching signals are depicted in red color as shown in the fig. 1. 


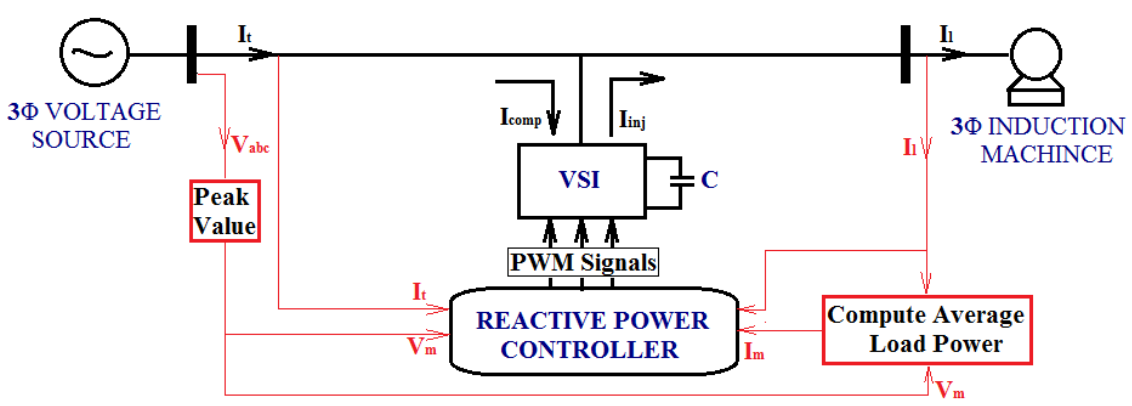

Figure. 1 Reactive Power ControllerBasedSystem

\section{Reactive Power Controller}

In this paper an innovative reactive power controller is proposed to improve the power factor. This controller performs the online computation of reactive power required by the load at all instants. $I_{t}$ is the total instantaneous current supplied from the sourceand can be calculated from the giveneqn. (1)

$I_{t}=I_{\text {comp }}+I_{m}$

Where, $I_{\text {comp }}$ is the current consumed by the VSI to charge the capacitorand $I_{m}$ is the peak value of the load current. When capacitor voltage is lesser than the source bus voltage, $I_{\text {comp }}$ will be injected to the VSI to charge the capacitor. So that de link voltage will be maintained constant. When reactive current component of the load increases, it will be compensated by VSI. Reactive current injected from the VSI $\left(I_{\text {inj }}\right)$ can be calculated from given eqn. (2.)

$I_{\text {inj }}=I_{t}-I_{l}$

Where $I_{l}$ is the instantaneous value of the load current. $I_{\text {comp }}$ can be calculated as given in the eqn. (3)

$W_{C}=1.5 * I_{\text {comp }} * V_{m}$

Where $V_{m}$ is the peak value of the source voltage, $W_{C}$ is the energy stored in the capacitor can be calculated as given in the eqn. (4).

$\mathrm{W}_{\mathrm{c}}=\left(\frac{1}{2}\right) * \mathrm{C} *\left[\mathrm{~V}_{\mathrm{dc}}^{2}\right]$

Where $V_{d c}$ is taken from the difference between reference voltage $\left(V_{d r e f}\right)$ and actual capacitor voltage $\left(V_{a c t}\right)$ as given in the eqn. (5).

$V_{d c}=V_{d r e f}-V_{a c t}$

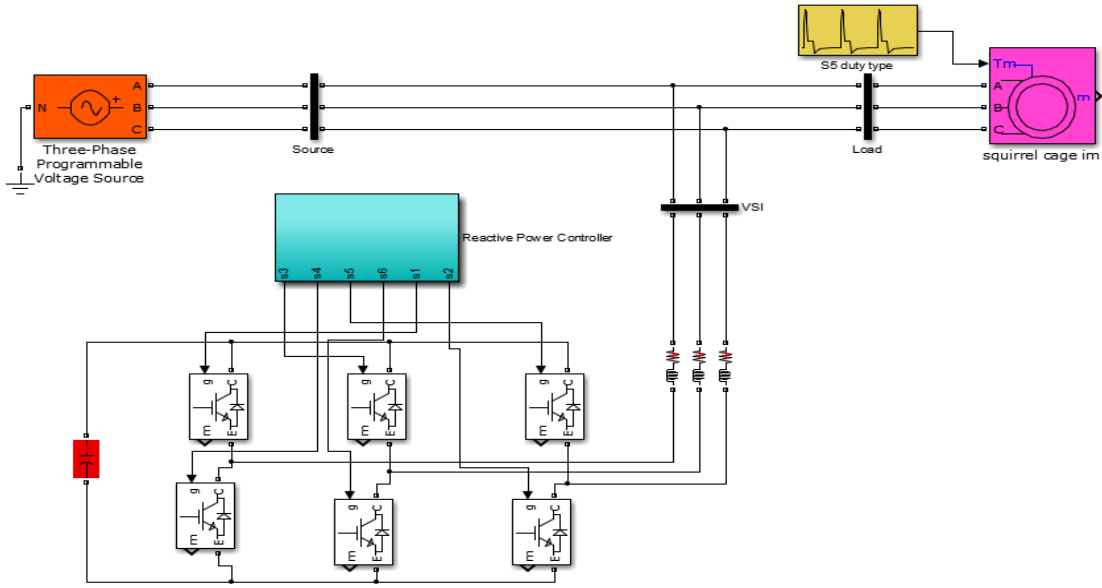

Fig. 2. Simulation diagram of complete system

If $V_{d c}$ is lesser than $V_{m}$ then capacitor will be charged. As three phase induction machine is operated with difference duty types, the inductive nature of the motor also changes. Real current component $\left(I_{p}\right)$ and reactive current $\left(I_{q}\right)$ consumed by the load also changes. Instantaneous load current consumed by the machine is given as $I_{l}=I_{p}+I_{q}$

Therefore injected current can be written as

$I_{\text {inj }}=I_{t}-\left(I_{p}+I_{q}\right)$.

Increase in $I_{p}$ will be compensated by source generator and $I_{q}$ will be compensated by VSI. 


\section{Simulation Circuit}

Proposed circuit is simulated using Matlab-simulink. A balanced source is connected to $3 \Phi$ squirrel cage induction motor in parallel with VSI. Simulation has been carried out for S3, S4 and S5. S5 duty type mechanical load is shown in the fig. 2. Three phase programmable voltage source is used to generate $3 \Phi$ balanced supply.

From source and load buses, feedback parameters are called for computation to generate PWM signals. Capacitor voltage source inverter is used to inject reactive power required by the load at different duty types. Current smoothening inductor is connected in series with VSI as shown in fig. 2.

\section{Simulation Results}

For S3, S4 and S5 duty types simulation is carried out. And the power factor values for after and before compensation is also added here.

A) .S3 Duty type of load: In this, a sequence of identical duty cycle, each consisting of a period of operation at a constant load and rest are analyzed. Cyclic Duration Factor(CDF) is the ratio of loading including starting, running and electric braking and to the duration of the duty cycle expressed as percentage as given in the eqn. 7 .

$C D F=\left[\frac{\text { time taken for running }(S)}{\text { time taken for running }(S)+\text { time taken for rest }(S)}\right] \times 100$

$C D F=\left(\frac{0.5}{0.5+0.75}\right) \times 100=40 \%$

For S3 duty type $40 \% \mathrm{CDF}$ is considered for simulation as shown in the fig. 3a.

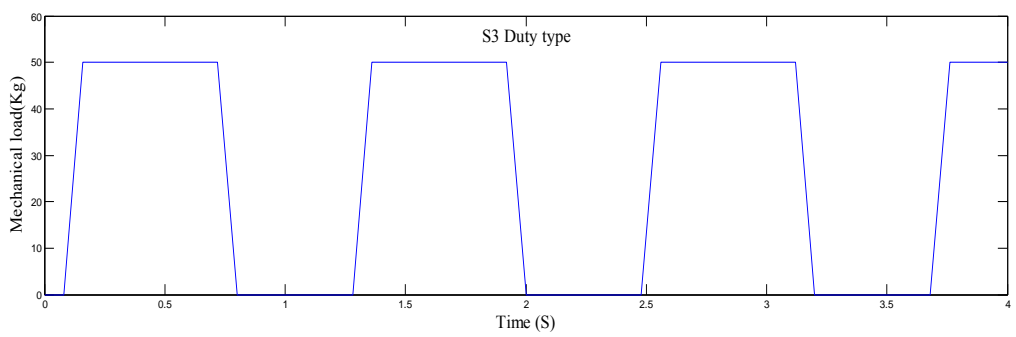

Fig. 3a. S3 duty type

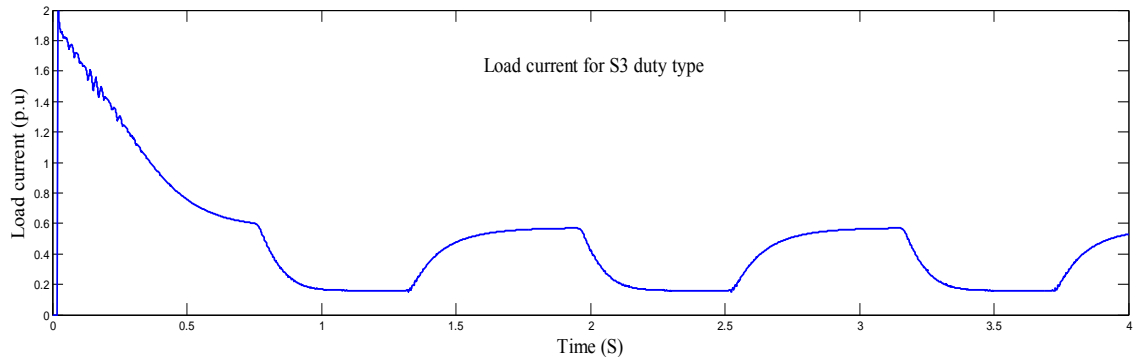

Fig. 3b. Load current for S3 duty type

Current consumed by the $3 \Phi$ squirrel cage induction motor for S3 duty type of load is shown in the fig. $3 \mathrm{~b}$. It is observed that theaverage power factor before compensation is 0.5 as depicted in the fig. 3c. After reactive power compensation, power factor is improved to 0.94 as shown in the fig. $3 \mathrm{~d}$.

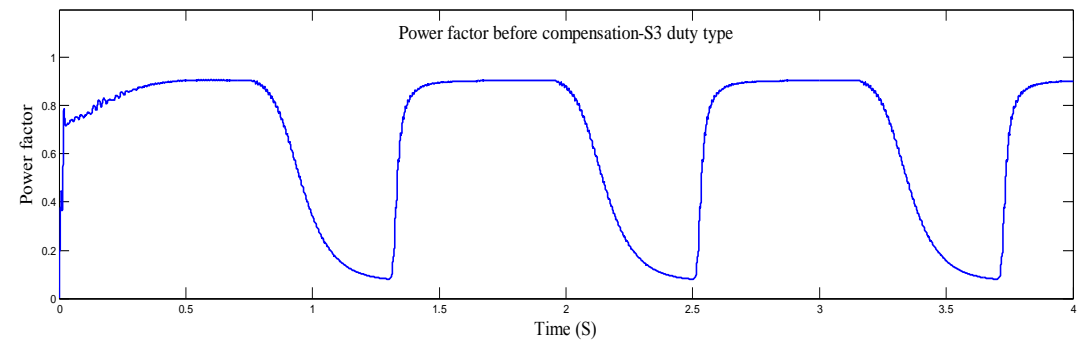

Fig. 3c. Power factor before compensation-S3 duty type 


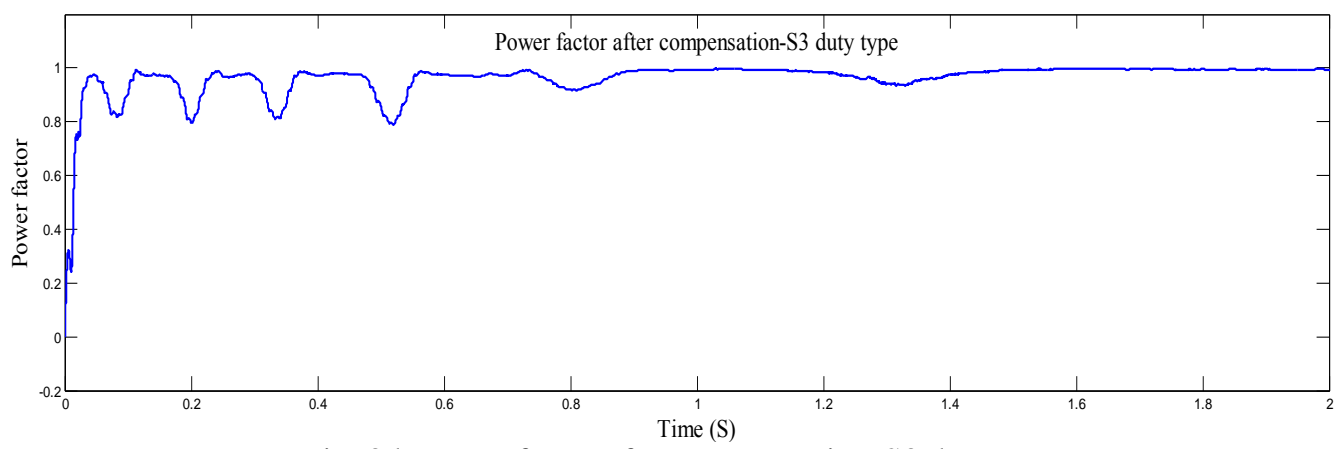

Fig. 3d. Power factor after compensation-S3 duty type

a). S4 Duty type of load: In this, a sequence of identical duty cycle, each consisting of a period of starting, running and rest are analyzed resulting in outputs as shown in the fig. 4a.

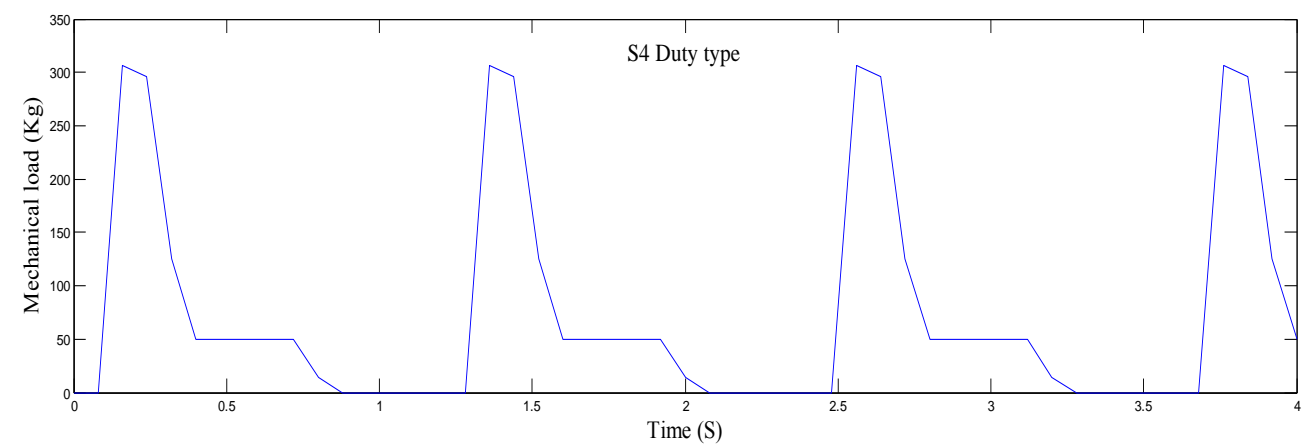

Fig. 4a. S4 duty type

The following time periods are considered for S4 duty type.

- $\quad$ time taken for starting $=0.35 \mathrm{~S}$

- $\quad$ time taken for running $=0.4 \mathrm{~S}$

- $\quad$ time taken for rest $=0.5 \mathrm{~S}$

$C D F=\left[\frac{\text { time taken for starting }+ \text { time taken for running }}{\text { time taken for starting }+ \text { time taken for running }(S)+\text { time taken for rest }}\right] \times 100$

$C D F=\left(\frac{0.35+0.4}{0.35+0.4+0.5}\right) \times 100=60 \%$

The current consumed by the motor during S4 duty type is depicted in the fig. 4b. From the figure it is observed that starting current is raised to 2 p.u. and no load current is 0.2 p.u.

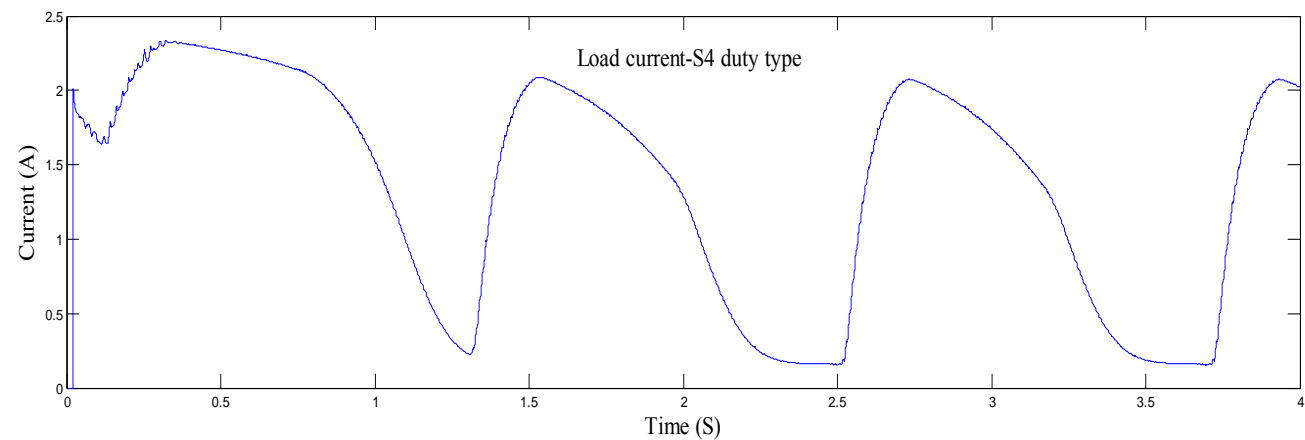

Fig. 4b. Load current for S4 duty type

Before compensation, it is observed that average power factor is 0.6 as shown in the fig. 4c. After compensation, it is improved to 0.9 for S4 duty type of load. 


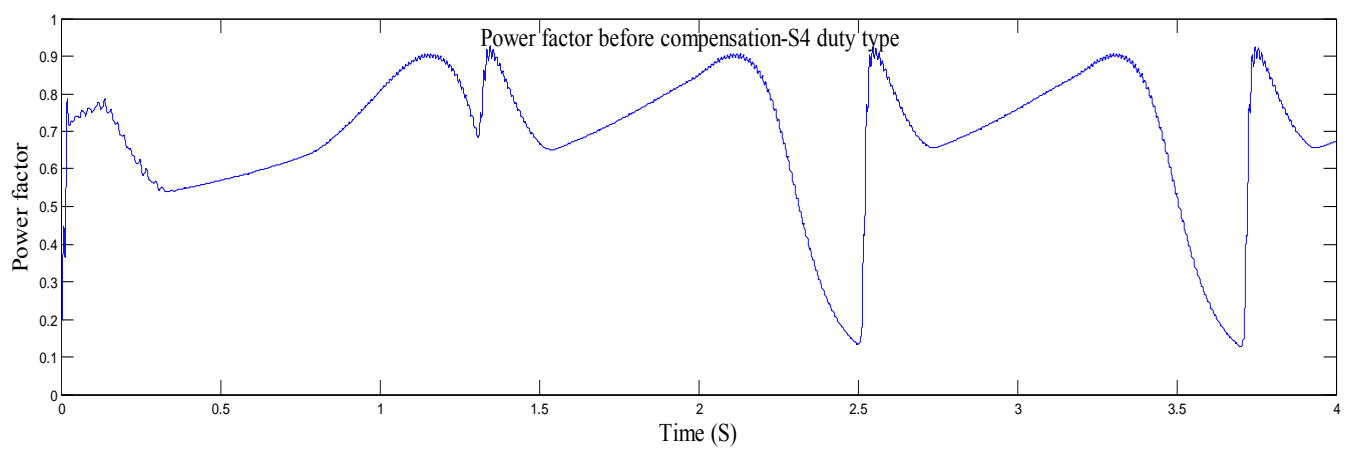

Fig. 4c. Power factor before compensation-S4 duty type

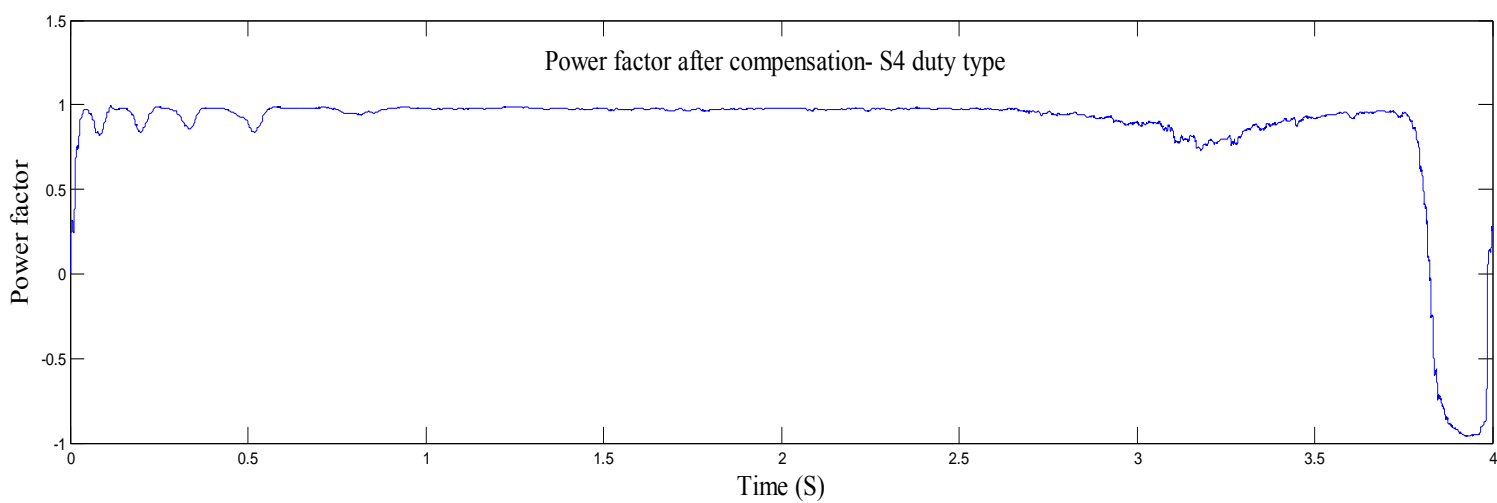

Fig. 4d. Power factor after compensation-S4 duty type

a). S5 Duty type of load: In this, a sequence of identical duty cycle, each consisting of a period of starting, running, electric braking and rest as shown in the fig. $5 \mathrm{a}$.

The following time periods are considered for S5 duty type.

- $\quad$ time taken for starting $=1.6 \mathrm{~S}$

- $\quad$ time taken for running $=1.4 \mathrm{~S}$

- $\quad$ time taken for electric braking $=2 \mathrm{~S}$

- $\quad$ time taken for rest $=2 \mathrm{~S}$

$C D F=\left[\frac{\text { time taken for starting }+ \text { time taken for running }+ \text { braking time }}{\text { time taken for starting }+ \text { time taken for running }(S)+\text { braking time }+ \text { time taken for rest }}\right] \times 100 \ldots$

$C D F=\left(\frac{1.6+1.4+2}{1.6+1.4+2+2.6}\right) \times 100=60 \%$

From eqn. (7), it is observed that $60 \% \mathrm{CDF}$ is considered for S5 duty type of load.

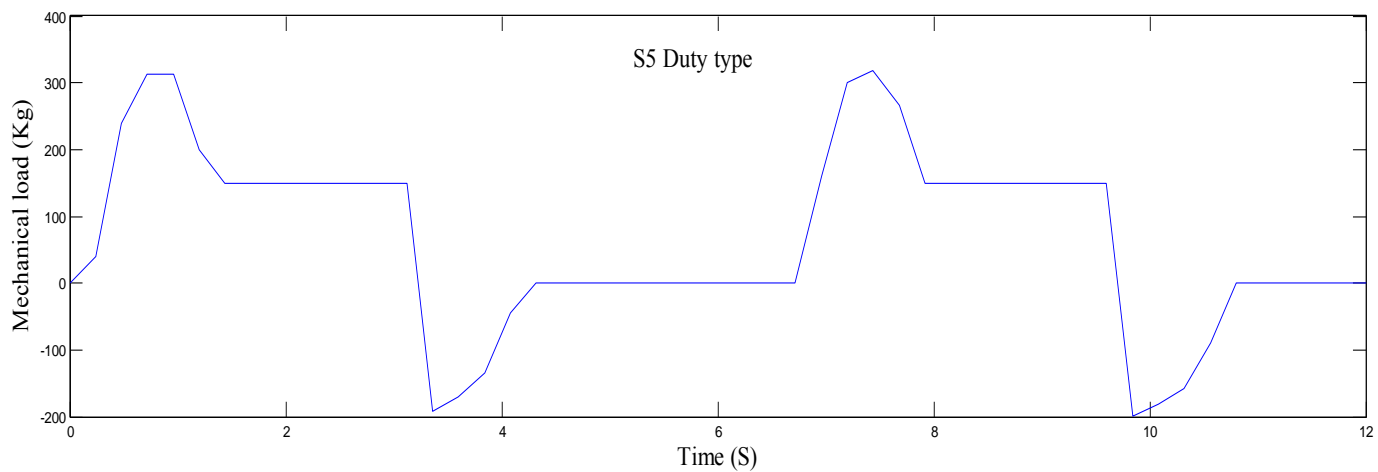

Fig. 5a. S5 duty type

From fig. $5 b$, it is observed that the magnitude of the load current is raised to 2 p.u. during starting and electric braking period. Under no load condition, the magnitude of the current is 0.2 p.u. 


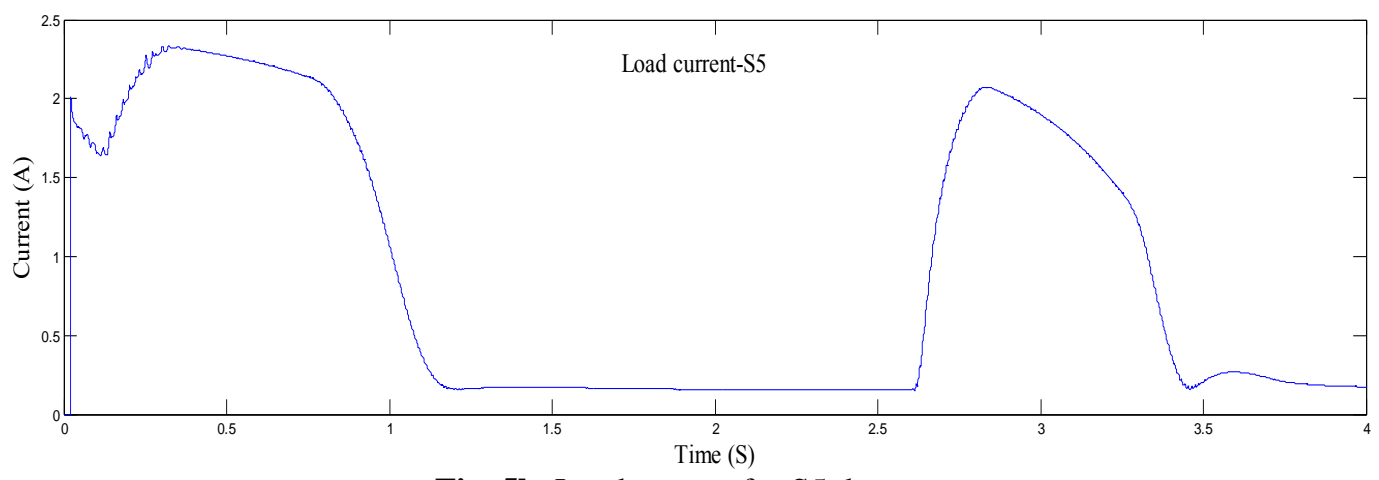

Fig. 5b. Load current for S5 duty type

Average power factor value before compensation is around 0.4 . With reference to the table. 1 , the penalty is about $2 \%$ percent of the current consumption for every reduction of 0.01 power factor value from 0.90 .

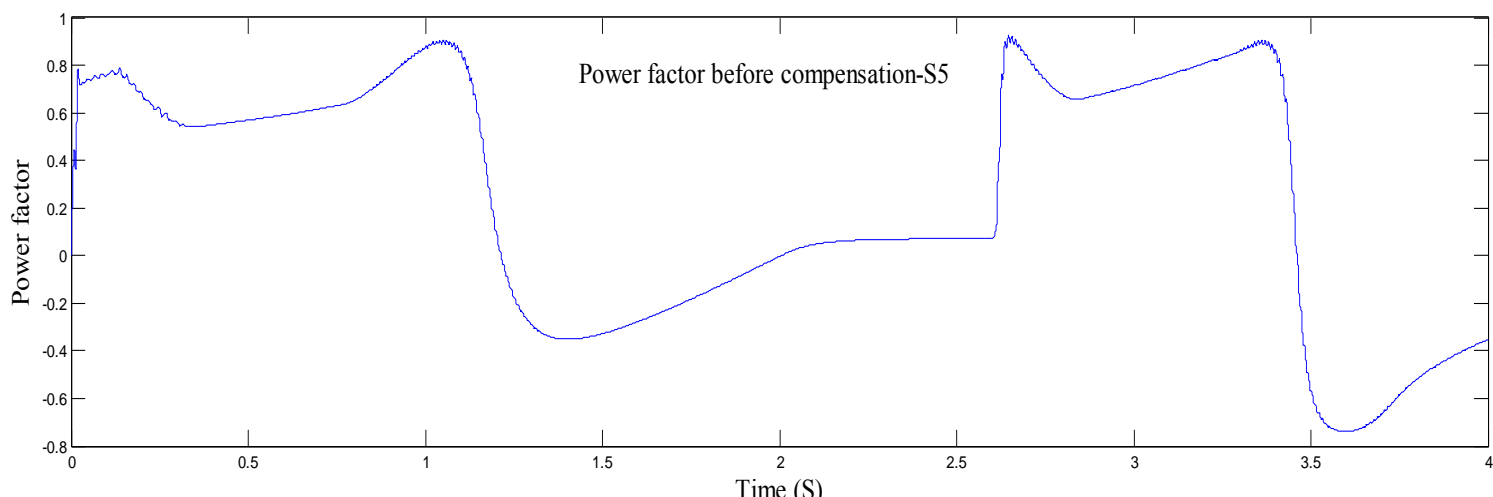

Fig. 5c. Power factor before compensation-S5 duty type

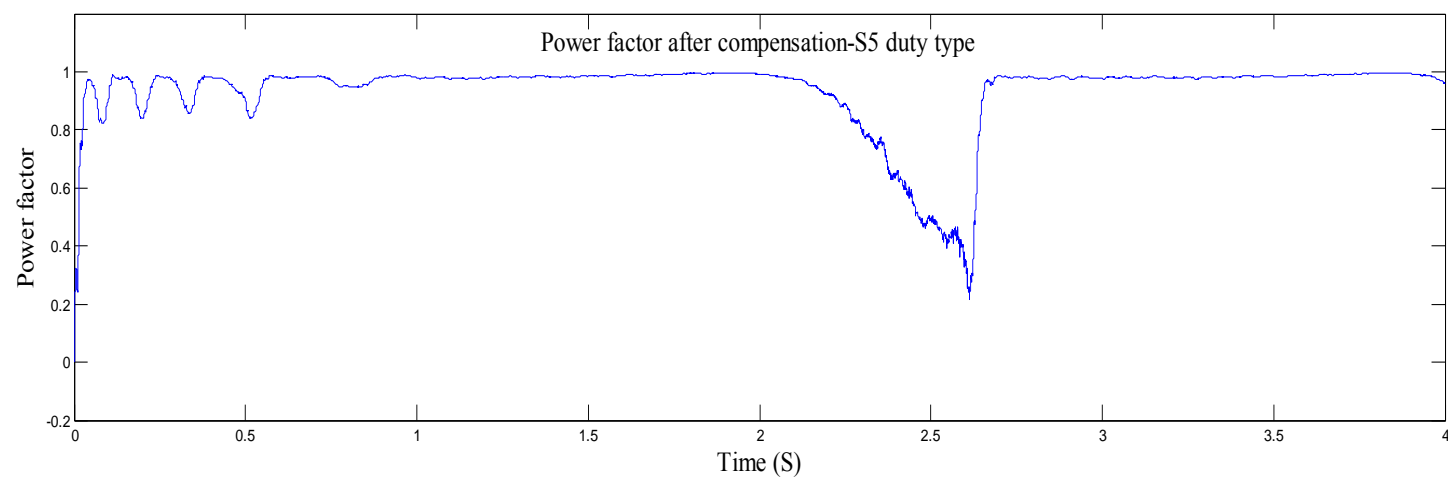

Fig. 5d. Power factor after compensation-S5 duty type

After reactive power compensation, average power factor is improved to 0.85 as shown in the fig. $5 \mathrm{~d}$.

\section{Conclusion}

Industries using inductive loads with different duty types face the problem of reduced power factor. This reduction in the power factor value adversely results in the increased penalty to Electricity board. Focusing on this, an effective method of reactive power compensation method was proposed in order to improve the power factor value of the industries with different types of duty types. The proposed reactive power controller was analyzed with different duty types and the simulation results are shown. From the output results, it is observed thatusing reactive power controller the penalty amount for power factor change is greatly reduced for all types of duty types. The designed controller can also be used for other types of linear and non-linear load for power factor improvement. 


\section{References}

[1] J.S. Moghani and Heidari, High efficient low cost induction motor drive for residential applications,SPEEDAM 2006. Taormina, May 2006, 1399-1402.

[2] YM. Irwan ; M. Irwanto ; I. SafwatiImprovement of induction machine performance using power factor correction , Electrical System Engineering Department, tahan, 21-22 June 2011, 472 - 476

[3] E. Muljadi ; Dept. of Electr. Eng., California State Univ., USA ; T. A. Lipo ; D. W. NovotnyPower factor enhancement of induction machines by means of solid-state excitationIEEE Transactions, 06 August 2002, $409-418$.

[4] A. El Fadili ; EMI, LAII, Rabat, Marocco, France ; F. Giri ; A. El Magri ; L. DugardInduction motor control in presence of magnetic saturation Speed regulation and power factor correction, June 2011, San Francisco, 5406 - 5411.

[5] Eel-Hwan Kim ; Cheju Nat. Univ., South Korea ; Jae-Hong Kim ; Gil-Su Lee , Power factor control of a doubly fed induction machine using fuzzy logic, 2001, Shenyang, Aug 2001747 - 750

[6] KhoudirMarouani ; LCM-UER-ELT, Ecole Militaire Polytech., Algiers, Algeria ; Kamel Nounou ; Mohamed Benbouzid ; Bekheïra Tabbache, Power factor correction of an electrical drive system based on multiphase machines ICGE 2014, March 2014Sfax, 152 157. 